\title{
PECAM-1 Leu125Val (rs688) Polymorphism and Diabetic Nephropathy in Caucasians with Type 2 Diabetes Mellitus
}

\author{
Matej Završnik, ${ }^{1}$ Stojan Kariž, ${ }^{2}$ Jana Makuc, ${ }^{3}$ Maja Šeruga, \\ Ines Cilenšek, ${ }^{5}$ and Daniel Petrovič ${ }^{5}$ \\ ${ }^{1}$ University Medical Centre Maribor, Clinic for Internal Medicine, Department for Diabetes and Metabolic Diseases, Maribor, Slovenia \\ ${ }^{2}$ General Hospital Izola, Department of Internal Medicine, Izola, Slovenia \\ ${ }^{3}$ General Hospital Slovenj Gradec, Department of Internal Medicine, Slovenj Gradec, Slovenia \\ ${ }^{4}$ General Hospital Murska Sobota, Department of Internal Medicine, Murska Sobota, Slovenia \\ ${ }^{5}$ Faculty of Medicine, Institute of Histology and Embryology, University of Ljubljana, Ljubljana, Slovenia
}

Correspondence should be addressed to Daniel Petrovič; dp.petrovic@gmail.com

Received 20 September 2016; Accepted 7 December 2016

Academic Editor: Ekaterina A. Ivanova

Copyright (C) 2016 Matej Završnik et al. This is an open access article distributed under the Creative Commons Attribution License, which permits unrestricted use, distribution, and reproduction in any medium, provided the original work is properly cited.

Objectives. Platelet endothelial cell adhesion molecule-1 (PECAM-1) plays a key role in the transendothelial migration of circulating leukocytes during inflammation and in the maintenance of vascular endothelial integrity. We hypothesized that genetic variation in PECAM-1 gene could be associated with diabetic nephropathy (DN) and with the level of soluble PECAM-1 in Caucasians with type 2 diabetes mellitus (T2DM). Design and Methods. We analyzed the rs688 single nucleotide polymorphism of PECAM-1 gene C373G (Leu125Val) at exon 3, which encodes the first extracellular Ig-like domain that mediates the homophilic binding of PECAM-1, in 276 T2DM subjects with documented DN (cases) and 375 T2DM subjects without DN (controls), using a polymerase chain reactionrestriction fragment length polymorphism (PCR-RFLP) strategy. Level of plasma soluble PECAM-1 (sPECAM-1) was measured by ELISA in a subpopulation of 120 diabetics with DN. Results. We found no association between the Leul25Val polymorphism and DN in subjects with T2DM. Likewise, the Leu125Val polymorphism was not associated with serum sPECAM-1 levels in a subpopulation of 120 diabetics with DN. Conclusion. The Leu125Val polymorphism of PECAM-1 and the level of sPECAM-1 are not associated with DN in T2DM subjects of Slovenian origin.

\section{Introduction}

Diabetic nephropathy (DN) is the leading cause of endstage renal disease and a major risk factor for cardiovascular disease $[1,2]$. Patients with DN have a higher risk of mortality, mainly due to cardiovascular complications, in comparison with diabetic patients without nephropathy [2]. As the number of patients with type 2 diabetes mellitus (T2DM) with end-stage renal disease has increased significantly over the past two decades, more research is required to discover new approaches to prevent or slow this worsening of renal function. Genetic susceptibility seems important in the pathogenesis of $\mathrm{DN}$ according to variable incidence rates of DN between different ethnic groups, aggregation of DN and diabetic end-stage renal disease in families, and high heritability estimates for diabetic renal histologic alterations, glomerular filtration rate, and albuminuria [3]. Identification of genes implicated in the basic mechanisms contributing to onset and advancement of DN is crucial for developing novel preventive and therapeutic strategies.

Inflammatory processes play a central role in the development and progression of DN. Inflammation is characterized by leukocyte infiltration at every stage of renal involvement and by increased expression of adhesion molecules, chemokines, and proinflammatory cytokines [1]. Increased levels of cell adhesion molecules in T2DM were shown to be strongly associated with both $\mathrm{DN}$ and cardiovascular disease complications and mortality [4].

Platelet endothelial cell adhesion molecule-1 (PECAM1) is a multifunctional vascular cell adhesion molecule and 
signaling molecule of the immunoglobulin (Ig) superfamily that is expressed on the surface of circulating leukocytes and platelets. PECAM-1 is also highly expressed on endothelial cells, where it is an important component of endothelial cell intercellular junctions in vascular beds [5]. The 130 $\mathrm{kDa}$ glycoprotein entails a single-chain molecule of six Iglike extracellular homology domains, a 19-residue transmembrane portion, and a 118-residue cytoplasmic tail [6]. The extracellular domain of PECAM-1 mediates homo- and heterophilic interactions, which can occur via the first Nterminal Ig homology domain, while the cytoplasmic region is involved in the transduction of various cellular signals [7].

As a signaling adhesion molecule, PECAM-1 serves various proinflammatory and anti-inflammatory functions and thus plays a crucial role in the regulation of vascular inflammatory response [8]. Proinflammatory functions of PECAM1 comprise the facilitation of leukocyte transendothelial migration and the transduction of mechanical signals in endothelial cells originating from fluid shear stress, whereas PECAM-1 anti-inflammatory effects include the dampening of leukocyte activation, suppression of proinflammatory cytokine production, and the maintenance and restoration of vascular barrier integrity [8]. PECAM-1 homophilic interactions, which occur through its first extracellular domain, are required for leukocyte transmigration [9] and have an important role in interendothelial cell bindings and regulation of vascular permeability [5].

PECAM-1 is encoded by a $75 \mathrm{~kb}$ gene that is located near the end of the long arm of chromosome 17 (17q23) and comprises 16 exons [10]. The rs668 polymorphism (C373G) in exon 3 of PECAM-1 gene at codon 125 causes a mutation of leucine to valine (Leu125Val). The Leu125Val polymorphism has been shown to be related to coronary artery disease [1113], ischemic stroke [14], atherosclerotic cerebral infarction [15], bronchial asthma [16], deep vein thrombosis [17], and sepsis [18]. However, the results of the association genetic studies published so far have not been unequivocal $[19,20]$.

Notably, our study group was earlier able to confirm an association between Leu125Val polymorphism and myocardial infarction in subjects with T2DM [21]. As patients with DN have a substantially increased risk of developing cardiovascular complications, we hypothesized that PECAM1 may be an important factor involved in both micro- and macrovascular pathogenesis of T2DM. Therefore, we investigated the relationship between the Leu125Val polymorphism (rs668) in PECAM-1 gene and DN in subjects with T2DM. We also tested the association between the aforementioned polymorphism and the serum concentration of sPECAM-1 in a subpopulation of T2DM subjects with DN.

\section{Patients and Methods}

In this cross-sectional case-control study we enrolled 651 unrelated Caucasians with T2DM of more than 10 years duration from outpatient clinics of the University Medical Centre Maribor and General Hospitals, Murska Sobota and Slovenj Gradec. The study group consisted of 276 subjects with DN (cases) and 375 subjects without clinical signs of
DN (control group). Patients were classified as having T2DM according to the current American Diabetes Association criteria [22]. Diagnosis of DN was made according to WHO (World Health Organization) 1999 diagnostic criteria [23].

To avoid the confounding effect of impaired kidney function, patients with overt nephropathy were not enrolled in the study. Patients with poor glycaemic control, significant heart failure (NYHA II-IV), alcoholism, infection, and other causes of renal disease were also excluded. The study was approved by the national medical ethics committee and was performed in compliance with the Helsinki Declaration. After an informed consent for the participation in the study was obtained, a detailed interview was conducted. Information on smoking, presence, and family history of cardiovascular disease, duration of arterial hypertension and T2DM, T2DM management and complications (retinopathy, neuropathy, and diabetic foot), therapy, and routine laboratory measurements were obtained from their medical records.

2.1. Biochemical Analyses. Total cholesterol, low-density lipoproteins (LDL), high-density lipoproteins (HDL), triglycerides, cystatin $\mathrm{C}$, fasting glucose, glycated hemoglobin (HbAlc), urea, and creatinine were determined by standard biochemical methods. For each patient, albumin to creatinine ratio was determined in three urine samples, according to diagnostic criteria. Cystatin C and MDRD study equation were used to estimate glomerular filtration rate (eGFR).

2.2. Determination of sPECAM-1 Level. Level of plasma soluble PECAM-1 (sPECAM-1) was measured by ELISA in a subpopulation of 120 diabetics with $\mathrm{DN}$.

2.3. Genotyping. After the genomic DNA was extracted with FlexiGene DNA isolation kit (Qiagen GmbH, Hilden, Germany) polymorphism C373G (rs668) of PECAM-1 gene was genotyped with KASP genotyping chemistry in UK (KBioscience Limited, acquired by LGC Genomics; Acquirer Information: LGC Genomics Ltd., Unit 1-2 Trident Industrial Estate, Hoddesdon, Hertfordshire, United Kingdom) according to standard protocol as follows: hot-start activation $94^{\circ} \mathrm{C}$ for 15 minutes, 10 cycles at $94^{\circ} \mathrm{C}$ for 20 seconds, at $61-55^{\circ} \mathrm{C}$ for 60 seconds, and 26 cycles at $94^{\circ} \mathrm{C}$ for 20 seconds and at $55^{\circ} \mathrm{C}$ for 60 seconds.

2.4. Statistical Analysis. Statistical analysis was performed using the SPSS program for Windows version 19 (SPSS Inc., Illinois). Continuous clinical data were compared by unpaired Student's $t$-test, while chi-square test was used to compare discrete variables and genotype distributions. Data were presented as mean $\pm \mathrm{SD}$ (continuous variables) or as the number and percent of patients (categorical variables). Further, all variables that showed significant differences by univariate analysis (with a $p$ value $<0.05$ considered significant) were analyzed together in a logistic regression analysis. A $p<0.05$ was considered statistically significant. The deviation from Hardy-Weinberg equilibrium (HWE) was assessed by the exact test (https://ihg.gsf.de/). 
TABLE 1: Clinical and laboratory characteristics of cases and controls.

\begin{tabular}{|c|c|c|c|}
\hline & Cases $(\mathrm{DN}+)$ & Controls (DN-) & Sig. $(p)$ \\
\hline Number & 276 & 375 & \\
\hline $\operatorname{Sex}(M)$ & $59.1 \%$ & $52.4 \%$ & 0.1 \\
\hline Age (years) & $64.75 \pm 9.15$ & $63.75 \pm 8.0$ & 0.13 \\
\hline Duration of T2D (years) & $14.71 \pm 7.97$ & $14.60 \pm 6.73$ & 0.84 \\
\hline Duration of hypertension (years) & $12.23 \pm 9.88$ & $10.52 \pm 8.22$ & 0.02 \\
\hline $\mathrm{SBP}[\mathrm{mmHg}]$ & $155.27 \pm 18.92$ & $149.84 \pm 19.63$ & $<0.001$ \\
\hline $\mathrm{DBP}[\mathrm{mmHg}]$ & $84.87 \pm 11.63$ & $84.06 \pm 11.42$ & 0.36 \\
\hline BMI & $31.3 \pm 4.68$ & $30.77 \pm 5.0$ & 0.23 \\
\hline Active smokers & $6.6 \%$ & $8.9 \%$ & 0.31 \\
\hline CVD & $20.0 \%$ & $12.2 \%$ & 0.007 \\
\hline Family history of CVD & $41.3 \%$ & $58.7 \%$ & 0.91 \\
\hline $\mathrm{DR}$ & $37.8 \%$ & $24.6 \%$ & $<0.001$ \\
\hline Duration of DR (years) & $3.94 \pm 3.11$ & $6.54 \pm 7.03$ & 0.23 \\
\hline DNeur & $9.1 \%$ & $6.0 \%$ & 0.38 \\
\hline $\mathrm{DF}$ & $15.5 \%$ & $8.1 \%$ & 0.03 \\
\hline S-HbAlc $[\%]^{1}$ & $7.98 \pm 1.38$ & $7.65 \pm 1.14$ & 0.001 \\
\hline S-fasting glucose $[\mathrm{mmol} / \mathrm{l}]$ & $9.03 \pm 2.76$ & $8.51 \pm 2.53$ & 0.01 \\
\hline $\mathrm{S}-\mathrm{Hb}[\mathrm{g} / \mathrm{l}]$ & $139.39 \pm 14.91$ & $139.40 \pm 12.96$ & 0.99 \\
\hline S-urea $[\mathrm{mmol} / \mathrm{l}]$ & $7.35 \pm 3.73$ & $6.25 \pm 1.91$ & $<0.001$ \\
\hline S-creatinine $[\mu \mathrm{mol} / \mathrm{l}]$ & $93.13 \pm 58.21$ & $78.44 \pm 20.15$ & $<0.001$ \\
\hline Male sex & $101.57 \pm 61.84^{*}$ & $84.28 \pm 19.94^{*}$ & $<0.001^{*}$ \\
\hline Female sex & $79.7 \pm 49.21^{* *}$ & $71.91 \pm 18.35^{* *}$ & $<0.001$ \\
\hline eGFR [MDRD equation, $\mathrm{ml} / \mathrm{min}$ ] & $72.6 \pm 19.74$ & $75.22 \pm 15.16$ & 0.22 \\
\hline male sex & $71.97 \pm 19.45^{*}$ & $77.66 \pm 14.33^{*}$ & $0.002^{*}$ \\
\hline female sex & $74.31 \pm 20.72^{* *}$ & $72.45 \pm 15.69^{* *}$ & $0.13^{* *}$ \\
\hline S-cystatin C [mg/l] & $0.95 \pm 0.48$ & $0.78 \pm 0.21$ & $<0.001$ \\
\hline S-Total cholesterol [mmol/l] & $4.62 \pm 1.17$ & $4.55 \pm 0.99$ & 0.42 \\
\hline $\mathrm{S}-\mathrm{HDL}[\mathrm{mmol} / \mathrm{l}]$ & $1.23 \pm 0.35$ & $1.26 \pm 0.36$ & 0.29 \\
\hline S-LDL $[\mathrm{mmol} / \mathrm{l}]$ & $2.59 \pm 0.95$ & $2.57 \pm 0.80$ & 0.73 \\
\hline S-TG [mmol/l] & $2.08 \pm 1.6$ & $1.83 \pm 1.24$ & 0.04 \\
\hline $\mathrm{U}$-albumin/creatinine ratio $[\mathrm{g} / \mathrm{mol}]$, sample no. 1 & $27.49 \pm 55.46$ & $1.57 \pm 3.05$ & $<0.001$ \\
\hline U-albumin/creatinine ratio $[\mathrm{g} / \mathrm{mol}]$, sample no. 2 & $23.13 \pm 39.34$ & $1.60 \pm 3.67$ & $<0.001$ \\
\hline $\mathrm{U}$-albumin/creatinine ratio $[\mathrm{g} / \mathrm{mol}]$, sample no. 3 & $23.36 \pm 42.49$ & $1.62 \pm 2.49$ & $<0.001$ \\
\hline
\end{tabular}

The values represent mean \pm standard deviation. Bold indicates statistically significant results.

${ }^{1}$ The average value for hemoglobin Alc (HbAlc).

${ }^{*}$ Comparing eGFR in men with DN and men without DN.

${ }^{* *}$ Comparing women with DN and women without DN.

\section{Results}

The demographic and clinical characteristics of the cases and control subjects are listed in Table 1 . There were no significant differences between groups with respect to age, sex, duration of T2DM, diastolic blood pressure, body mass index (BMI), smoking status, family history of cardiovascular disease (CVD), duration of diabetic retinopathy (DR), estimated glomerular filtration rate (eGFR), serum hemoglobin $(\mathrm{Hb})$, total cholesterol, HDL, and LDL cholesterol levels. On the other hand, statistically significant differences were observed in the following parameters: duration of hypertension, systolic blood pressure, presence of cardiovascular disease (CVD), urine albumin to creatinine ratio, as well as serum fasting glucose, HbAlc, urea, creatinine, and triglyceride (TG) levels. Cases also showed significantly more chronic diabetic complications, such as diabetic retinopathy (DR) and diabetic foot (DF), but not diabetic neuropathy (DNeur).

Differences in parameters reflecting renal function (serum creatinine, cystatin C, eGFR, and urine albumin to creatinine ratio) confirmed chronic kidney disease in diabetic subjects with DN. Cystatin C was a better marker for estimation of renal function than eGFR (MDRD equation $\mathrm{ml} / \mathrm{min}$ ). Cystatin $\mathrm{C}$ was significantly higher in subjects with $\mathrm{DN}(p<0,001)$ (Table 1).

The genotype distribution and allele frequencies of Leu125Val polymorphism in subjects with DN (cases) and those without DN (controls) are presented in Table 2. 
TABLE 2: Distribution of rs668 polymorphism genotypes and alleles in patients with diabetic nephropathy (cases) and in those without diabetic nephropathy (controls).

\begin{tabular}{lccc}
\hline & Cases (276) & Controls (375) & $p$ value \\
\hline rs668 & & & \\
GG & $56(20.4)$ & $64(17.0)$ & \\
GC & $144(52.0)$ & $189(50.3)$ & 0.3 \\
CC & $76(27.6)$ & $122(32.7)$ & \\
\hline G allele (\%) & $256(46.4)$ & $317(42.3)$ & 0.2 \\
C allele (\%) & $296(53.6)$ & $433(57.7)$ & \\
PHWE $^{\dagger}$ & 0.42 & 0.53 & \\
\hline
\end{tabular}

$\mathrm{PHWE}^{\dagger}=p$ values for the HWE were computed using Pearson's goodnessof-fit chi-square (1df).

Univariate analysis did not reveal significant differences in the genotype or allele frequencies between TD2M cases and controls (Table 2). The genotype distribution did not significantly deviate from a Hardy-Weinberg equilibrium (Table 2). Logistic regression analysis adjusted for different confounders did not reveal significant effect of the Leu125Val polymorphism on DN risk in subjects with T2DM (Table 3).

No association was found between the Leu125Val polymorphism and serum sPECAM-1 levels in a subpopulation of 120 diabetics with DN (Table 4).

\section{Discussion}

In the present case-control study that included 651 Caucasian subjects with T2DM, we failed to confirm an association between the rs688 single nucleotide polymorphism of PECAM-1 gene (Leu125Val) and DN. Likewise, no association was found between the Leul25Val polymorphism and serum sPECAM-1 levels in a subpopulation of 120 diabetics with DN.

$\mathrm{DN}$ is considered an inflammatory disease. Inflammatory cells are implicated at every stage of renal impairment and the extent of inflammatory cell accumulation in the kidney is closely related to $\mathrm{DN}$ [1]. A $130 \mathrm{kDa}$ adhesion molecule PECAM-1 is a crucial mediator of leukocyte migration through intercellular junctions of vascular endothelial cells [5] and may thus contribute to microand macrovascular inflammatory complications of T2DM. Hyperglycemia and oxidative stress have been shown to promote transendothelial migration of monocytes through phosphorylation of PECAM-1 [24, 25], whereas hyperinsulinaemia enhanced neutrophil transendothelial migration by increasing endothelial PECAM-1 expression via mitogenactivated protein kinase activation [26]. Abnormal angiogenesis may also play a significant role in the pathogenesis of DN [27]. PECAM-1 is involved in endothelial cell-cell and cell-matrix interactions and signal transduction, which are essential during angiogenesis [28]. Further, Kondo et al. have demonstrated that PECAM-1 is a critical modulator of endothelial cell adhesion, migration, and capillary morphogenesis in kidneys [6].
In normal kidneys, PECAM-1 is expressed on endothelial cells of glomerular and peritubular capillaries, whereas its expression is reduced in obliterated glomeruli with endothelial cell destruction, such as in diabetic glomerulosclerosis [29]. In animal models with reversible kidney injury, such as anti-Thyl treatment in rats, PECAM-1 expression increases during the recovery phase [30]. Thus, it seems that, under pathological conditions, compensatory PECAM-1 modulation may enable glomerular endothelial cell survival [31]. Recently, Cheung et al. showed that PECAM-1 signaling is both necessary and sufficient to prevent inflammationinduced endothelial cell death and confer immune privilege to the vascular endothelium [32]. Of interest, Baelde et al. have studied the messenger RNA expression profiles of diabetic glomeruli and PECAM-1 gene was found to be upregulated among other ninety-six overexpressed genes in comparison to the glomeruli from healthy individuals [33].

PECAM-1/PECAM-1 homophilic interactions, which are mediated by the first $\mathrm{NH}_{2}$-terminal Ig homology domain, are primarily responsible for leukocyte transmigration and play a vital role in the regulation of the endothelial barrier function [5]. The first IgG domain of PECAM-1 is encoded by the third exon of PECAM-1 gene that contains the Leu125Val polymorphism [10]. A single amino acid mutation of leucine to valine may affect the homophilic binding capability and therefore influence PECAM-1-mediated cellular interactions. The Leu125Val (L/V) polymorphism is in strong linkage disequilibrium with amino acid polymorphisms in exon 8 at codon 563 altering a serine to an asparagine $(\mathrm{S} / \mathrm{N})$ and in exon 12 at codon 670 altering an arginine to a glycine $(R / G)$ [10]. Goodman et al. have described an association between the LSR and VNG haplotypes and leukocyte/endothelial interaction [34]. Namely, they showed that LSR/VNG heterozygous monocytes adhere better to endothelium under conditions of flow than LSR/VNG homozygous cells [34]. In accordance with the possible functional effect, the Leu125Val polymorphism has been shown to be associated with a number of cardiovascular and cerebrovascular diseases [1115] and with sepsis [18].

However, the results of the association genetic studies published so far have not been unequivocal. Similar to our study, Kamiuchi et al. were unable to prove an association between PECAM-1 Val125Leu polymorphism and the presence of diabetic retinopathy in subjects with T2DM [20], whereas Bazzaz et al. found no correlation between PECAM1 Val125Leu polymorphism and microangiopathic complications in subjects with type 1 diabetes [35]. In Japanese subjects with T2DM, PECAM-1 Val125Leu polymorphism was not associated with chronic kidney disease [36]. However, a possibility of a weak association of PECAM-1 Val125Leu polymorphism with chronic kidney disease was found in Japanese individuals with both T2DM and arterial hypertension [37]. The results from a recent meta-analysis suggested that Leu125Val polymorphism in PECAM-1 gene is not a susceptibility marker of coronary heart disease [19].

Contrary to our findings, several studies have reported an association between the circulating sPECAM-1 levels and the Leu125Val polymorphism $[12,14,15,17,18]$. The soluble plasma sPECAM-1 exists in two distinct forms: a 
TABLE 3: Logistic regression analysis adjusted for different confounders (duration of hypertension, systolic blood pressure, CVD, diabetic retinopathy, diabetic foot, $\mathrm{HbAlc}$, fasting glucose, urea, creatinine, cystatin $\mathrm{C}$, and urine albumin/creatinine ratio) according to codominant genetic model.

\begin{tabular}{|c|c|c|c|c|c|}
\hline $\begin{array}{l}\text { Inheritance } \\
\text { model }\end{array}$ & Genotype & Cases (276) & Controls (375) & $\begin{array}{l}\text { Unadjusted OR, } \\
95 \% \mathrm{CI} / p \text { value }\end{array}$ & $\begin{array}{c}\text { Adjusted OR, 95\% } \\
\mathrm{CI} / p^{\dagger} \text { value }\end{array}$ \\
\hline rs668 & GG & $56(20.4)$ & $64(17.0)$ & $1.42(0.89-2.24) / 0.1$ & $0.85(0.34-2.11) / 0.7$ \\
\hline \multirow{2}{*}{ Codominant } & GC & $144(52.0)$ & $189(50.3)$ & $1.23(0.86-1.75) / 0.3$ & $1.65(0.83-3.26) / 0.9$ \\
\hline & $\mathrm{CC}$ & $76(27.6)$ & $122(32.7)$ & Reference & Reference \\
\hline
\end{tabular}

$p^{\dagger}$ values were adjusted for duration of hypertension, SBP, CVD, DR, DF, haemoglobin $\mathrm{A}_{1 \mathrm{C}}$, haemoglobin A1C (HbAlc), S-fasting glucose, S-urea, S-creatinine, $\mathrm{S}$-cystatin, and $\mathrm{U}$-albumin/creatinine ratio [g/mol], sample no. 1-no. 3 .

Odds ratio (OR); confidence interval (CI).

TABLE 4: The serum PECAM-1 levels in a subpopulation of 120 diabetics with DN according to different genotypes of rs668 polymorphism.

\begin{tabular}{lccc}
\hline Polymorphism & Genotype (number) & PECAM (ng/ml) & $p$ value \\
\hline \multirow{2}{*}{ rs668 } & GG $(25)$ & $95.6 \pm 21.7(86.6-104.5)$ & \\
& GC (61) & $96.0 \pm 22.5(90.3-101.8)$ & 0.9 \\
\hline
\end{tabular}

Values are mean \pm SD $(95 \%$ confidence interval).

transmembraneless $120 \mathrm{kDa}$ form and a truncated $90 \mathrm{kDa}$ form [38]. The transmembraneless sPECAM-1 is formed by alternative splicing of the transmembrane segment-encoding (exon 9) transcript upon cell activation, while the truncated form is generated by PECAM-1 proteolytic cleavage at the cell surface and shedding of the extracellular portion of PECAM1 into the plasma $[38,39]$. Soluble forms of PECAM- 1 can act as competitive inhibitors of membrane-bound PECAM-1 and by this means regulate the transmigration of leukocytes [9]. It has been suggested that, due to the localization of Leu125Val in the first loop of the extracellular domain of PECAM1 protein, the leucine to valine mutation may facilitate the cleavage of SPECAM-1 from cell surface and thus increase the serum SPECAM-1 level while decreasing the endothelial barrier function of PECAM-1 [18].

The inconsistencies among the results of our and other genetic association studies may be explained by differences in phenotype definition, the variation in the genetic or environmental background of the populations studied, the possibility of various gene-gene and gene-environment interactions, or insufficient sample size [40]. Although the number of subjects included in our study was relatively small, all the participants were recruited from a rather homogenous genetic and environmental background. In addition, the strength of the study is a rather long duration of T2DM in both cases and control subjects.

T2DM is a multifactorial disease arising from complex interactions between genetic makeup and environmental influences [41]. In order to advance our knowledge of the origin, onset, development, prevention, and treatment of T2DM, besides genetics, we will need to employ epigenomics, transcriptomics, proteomics, and other "omics" in a systematic approach [41]. Further, to unravel the intricate regulatory mechanisms and complex metabolic networks implicated in the pathophysiology of T2DM integrated multiomics methods will have to be applied. Recently, there has been rapid evolution of high-throughput technologies and platforms to assay global DNA, RNA, proteins, and metabolites. All of these "omics" techniques will generate massive amounts of quantitative experimental data, which will require advanced statistical and computational methods and systems biology approaches for successful integration [42]. In addition, the rapid progress of nanotechnology will undoubtedly complement and greatly empower the "omics" fields of medical research [43].

To conclude with, we were not able to prove an association between the Leu125Val polymorphism of the PECAM-1 gene and DN in subjects with T2DM, indicating that rs688 single nucleotide polymorphism is not a genetic marker for susceptibility to DN in Caucasians with T2DM.

\section{Competing Interests}

The authors declare that there is no conflict of interests regarding the publication of this paper.

\section{Authors' Contributions}

Matej Završnik and Stojan Kariž contributed equally to the manuscript.

\section{References}

[1] J. Donate-Correa, E. Martín-Núñez, M. Muros-de-Fuentes, C. Mora-Fernández, and J. F. Navarro-González, "Inflammatory Cytokines in Diabetic Nephropathy," Journal of Diabetes Research, vol. 2015, Article ID 948417, 9 pages, 2015.

[2] M. Afkarian, M. C. Sachs, B. Kestenbaum et al., "Kidney disease and increased mortality risk in type 2 diabetes," Journal of the American Society of Nephrology, vol. 24, no. 2, pp. 302-308, 2013.

[3] B. I. Freedman, M. Bostrom, P. Daeihagh, and D. W. Bowden, "Genetic factors in diabetic nephropathy," Clinical Journal of the American Society of Nephrology, vol. 2, no. 6, pp. 1306-1316, 2007. 
[4] T. Wu, K. C. Y. McGrath, and A. K. Death, "Cardiovascular disease in diabetic nephropathy patients: cell adhesion molecules as potential markers?" Vascular Health and Risk Management, vol. 1, no. 4, pp. 309-316, 2005.

[5] J. R. Privratsky and P. J. Newman, "PECAM-1: regulator of endothelial junctional integrity," Cell and Tissue Research, vol. 355, no. 3, pp. 607-619, 2014.

[6] S. Kondo, E. A. Scheef, N. Sheibani, and C. M. Sorenson, "PECAM-1 isoform-specific regulation of kidney endothelial cell migration and capillary morphogenesis," American Journal of Physiology-Cell Physiology, vol. 292, no. 6, pp. C2070C2083, 2007.

[7] S. Kitazume, R. Imamaki, K. Ogawa, and N. Taniguchi, "Sweet role of platelet endothelial cell adhesion molecule in understanding angiogenesis," Glycobiology, vol. 24, no. 12, pp. 12601264, 2014.

[8] J. R. Privratsky, D. K. Newman, and P. J. Newman, "PECAM-1: conflicts of interest in inflammation," Life Sciences, vol. 87, no. 3-4, pp. 69-82, 2010.

[9] J. P. Newton, C. D. Buckley, E. Y. Jones, and D. L. Simmons, "Residues on both faces of the first immunoglobulin fold contribute to homophilic binding sites of PECAM-1/CD31," The Journal of Biological Chemistry, vol. 272, no. 33, pp. 2055520563, 1997.

[10] M. S. Novinska, B. C. Pietz, T. M. Ellis, D. K. Newman, and P. J. Newman, "The alleles of PECAM-1," Gene, vol. 376, no. 1-2, pp. 95-101, 2006.

[11] J. Auer, T. Weber, R. Berent, E. Lassnig, G. Lamm, and B. Eber, "Genetic polymorphisms in cytokine and adhesion molecule genes in coronary artery disease," American Journal of PharmacoGenomics, vol. 3, no. 5, pp. 317-328, 2003.

[12] H. Wei, L. Fang, S. H. Chowdhury et al., "Platelet-endothelial cell adhesion molecule-1 gene polymorphism and its soluble level are associated with severe coronary artery stenosis in Chinese Singaporean," Clinical Biochemistry, vol. 37, no. 12, pp. 1091-1097, 2004.

[13] L. Fang, H. Wei, S. H. Chowdhury et al., "Association of Leu125Val polymorphism of platelet endothelial cell adhesion molecule-1 (PECAM-1) gene \& soluble level of PECAM-1 with coronary artery disease in Asian Indians," Indian Journal of Medical Research, vol. 121, no. 2, pp. 92-99, 2005.

[14] Y.-S. Wei, Y. Lan, Y.-G. Liu, L.-Q. Meng, Q.-Q. Xu, and H.Y. Xie, "Platelet-endothelial cell adhesion molecule-1 gene polymorphism and its soluble level are associated with ischemic stroke," DNA and Cell Biology, vol. 28, no. 3, pp. 151-158, 2009.

[15] Y. Song, R. Zhao, L. Long, N. Zhang, and Y. Liu, "Leu125val polymorphism of platelet endothelial cell adhesion molecule-1 is associated with atherosclerotic cerebral infarction in chinese han population," International Journal of Clinical and Experimental Medicine, vol. 7, no. 12, pp. 5808-5813, 2014.

[16] E. Nadi, M. Hajilooi, D. Babakhani, and A. Rafiei, "Platelet endothelial cell adhesion molecule-1 polymorphism in patients with bronchial asthma," Iranian Journal of Allergy, Asthma and Immunology, vol. 11, no. 4, pp. 276-281, 2012.

[17] G. Li, Z. L. Han, H. G. Dong, X. Zhang, X. Q. Kong, and X. Jin, "Platelet endothelial cell adhesion molecule 1 gene $125 \mathrm{C} / \mathrm{G}$ polymorphism is associated with deep vein thrombosis," Molecular Medicine Reports, vol. 12, no. 2, pp. 2203-2210, 2015.

[18] W. Sun, F.-S. Li, Y.-H. Zhang, X.-P. Wang, and C.-R. Wang, "Association of susceptibility to septic shock with platelet endothelial cell adhesion molecule-1 gene Leu125Val polymorphism and serum sPECAM-1 levels in sepsis patients,"
International Journal of Clinical and Experimental Medicine, vol. 8, no. 11, pp. 20490-20498, 2015.

[19] T. Xia, X. Liu, C. J. Du, X. Jin, X. Q. Kong, and G. Li, "Association of leu125Val polymorphisms in the PECAM-1 gene with the risk of coronary heartdisease: a meta-analysis," International Journal of Clinical and Experimental Medicine, vol. 8, no. 2, pp. 22192225, 2015.

[20] K. Kamiuchi, G. Hasegawa, H. Obayashi et al., "Intercellular adhesion molecule-1 (ICAM-1) polymorphism is associated with diabetic retinopathy in Type 2 diabetes mellitus," Diabetic Medicine, vol. 19, no. 5, pp. 371-376, 2002.

[21] H. Reschner, A. Milutinovic, and D. Petrovič, "The PECAM1 gene polymorphism-a genetic marker of myocardial infarction," Central European Journal of Biology, vol. 4, no. 4, pp. 515520, 2009.

[22] American Diabetes Association, "Diagnosis and classification of diabetes mellitus," Diabetes Care, vol. 35, supplement 1, pp. S64-S71, 2011.

[23] World Health Organization, "Part 1: diagnosis and clasification of diabetes mellitus: report of a WHO consultation," in Definition, Diagnosis and Classification of Diabetes Mellitus and Its Complications, A. Alwan and H. King, Eds., Word Health Department of Noncommunicable Disease Surveillance, Geneva, Switzerland, 1999.

[24] V. Rattan, Y. Shen, C. Sultana, D. Kumar, and V. K. Kalra, "Glucose-induced transmigration of monocytes is linked to phosphorylation of PECAM-1 in cultured endothelial cells," American Journal of Physiology-Endocrinology and Metabolism, vol. 271, no. 4, part 1, pp. E711-E717, 1996.

[25] V. Rattan, C. Sultana, Y. Shen, and V. K. Kalra, "Oxidant stress-induced transendothelial migration of monocytes is linked to phosphorylation of PECAM-1," American Journal of Physiology-Endocrinology and Metabolism, vol. 273, no. 3, part 1, pp. E453-E461, 1997.

[26] M. Okouchi, N. Okayama, S. Imai et al., "High insulin enhances neutrophil transendothelial migration through increasing surface expression of platelet endothelial cell adhesion molecule-1 via activation of mitogen activated protein kinase," Diabetologia, vol. 45, no. 10, pp. 1449-1456, 2002.

[27] T. Nakagawa, T. Kosugi, M. Haneda, C. J. Rivard, and D. A. Long, "Abnormal angiogenesis in diabetic nephropathy," Diabetes, vol. 58, no. 7, pp. 1471-1478, 2009.

[28] S. Park, T. A. DiMaio, E. A. Scheef, C. M. Sorenson, and N. Sheibani, "PECAM-1 regulates proangiogenic properties of endothelial cells through modulation of cell-cell and cell-matrix interactions," American Journal of Physiology-Cell Physiology, vol. 299, no. 6, pp. C1468-C1484, 2010.

[29] I. A. Hauser, R. Riess, B. Hausknecht, H. Thüringer, and R. B. Sterzel, "Expression of cell adhesion molecules in primary renal disease and renal allograft rejection," Nephrology Dialysis Transplantation, vol. 12, no. 6, pp. 1122-1131, 1997.

[30] M. Isome, H. Fujinaka, E. Yaoita et al., "Involvement of endothelial cell adhesion molecules in the development of antiThy-1 nephritis," Experimental Nephrology, vol. 10, no. 5-6, pp. 338-347, 2002.

[31] S. Khan, S. Lakhe-Reddy, J. H. McCarty et al., "Mesangial cell integrin $\alpha \mathrm{v} \beta 8$ provides glomerular endothelial cell cytoprotection by sequestering TGF- $\beta$ and regulating PECAM-1," American Journal of Pathology, vol. 178, no. 2, pp. 609-620, 2011.

[32] K. Cheung, L. Ma, G. Wang et al., "CD31 signals confer immune privilege to the vascular endothelium," Proceedings of the 
National Academy of Sciences of the United States of America, vol. 112, no. 43, pp. E5815-E5824, 2015.

[33] H. J. Baelde, M. Eikmans, P. P. Doran, D. W. P. Lappin, E. De Heer, and J. A. Bruijn, "Gene expression profiling in glomeruli from human kidneys with diabetic nephropathy," American Journal of Kidney Diseases, vol. 43, no. 4, pp. 636-650, 2004.

[34] R. S. Goodman, C. M. Kirton, G. J. Oostingh et al., "PECAM-1 polymorphism affects monocyte adhesion to endothelial cells," Transplantation, vol. 85, no. 3, pp. 471-477, 2008.

[35] J. T. Bazzaz, M. M. Amoli, V. Pravica, B. Larijani, and I. V. Hutchinson, "PECAM-1 (CD31) gene polymorphisms in type 1 diabetes and its microangiopathic complications," Journal of Diabetes and Metabolic Disorders, vol. 10, pp. 1-13, 2011.

[36] T. Yoshida, K. Kato, K. Yokoi et al., "Association of genetic variants with chronic kidney disease in Japanese individuals with type 2 diabetes mellitus," International Journal of Molecular Medicine, vol. 23, no. 4, pp. 529-537, 2009.

[37] T. Yoshida, K. Kato, K. Yokoi et al., "Association of gene polymorphisms with chronic kidney disease in high- or low-risk subjects defined by conventional risk factors," International Journal of Molecular Medicine, vol. 23, no. 6, pp. 785-792, 2009.

[38] G. Fornasa, E. Groyer, M. Clement et al., "TCR stimulation drives cleavage and shedding of the ITIM receptor CD31," Journal of Immunology, vol. 184, no. 10, pp. 5485-5492, 2010.

[39] A. Goldberger, K. A. Middleton, J. A. Oliver et al., "Biosynthesis and processing of the cell adhesion molecule PECAM-1 includes production of a soluble form," The Journal of Biological Chemistry, vol. 269, no. 25, pp. 17183-17191, 1994.

[40] S. Kathiresan, C. Newton-Cheh, and R. E. Gerszten, "On the interpretation of genetic association studies," European Heart Journal, vol. 25, no. 16, pp. 1378-1381, 2004.

[41] M. Kussmann, M. J. Morine, J. Hager, B. Sonderegger, and J. Kaput, "Perspective: a systems approach to diabetes research," Frontiers in Genetics, vol. 4, article 205, 2013.

[42] Y. Doring, H. Noels, and C. Weber, "The use of highthroughput technologies to investigate vascular inflammation and atherosclerosis," Arteriosclerosis, Thrombosis, and Vascular Biology, vol. 32, no. 2, pp. 182-195, 2012.

[43] J. R. Heath, "Nanotechnologies for biomedical science and translational medicine," Proceedings of the National Academy of Sciences of the United States of America, vol. 112, no. 47, pp. 14436-14443, 2015. 


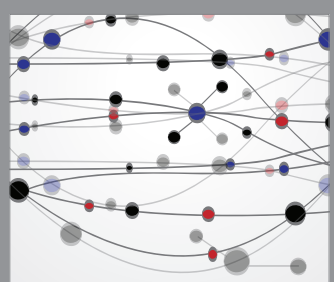

The Scientific World Journal
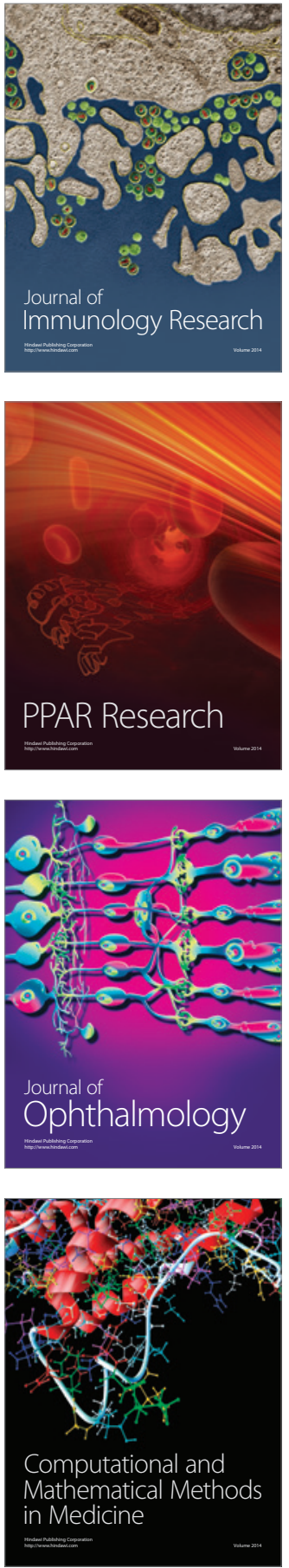

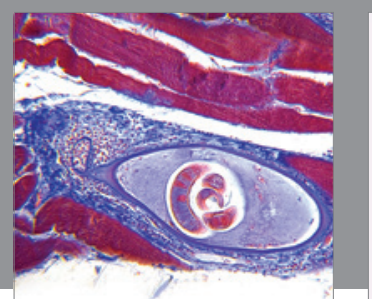

Gastroenterology Research and Practice

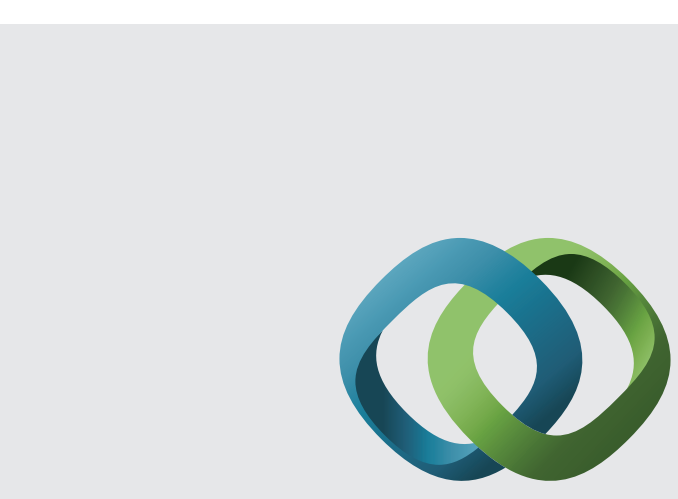

\section{Hindawi}

Submit your manuscripts at

http://www.hindawi.com
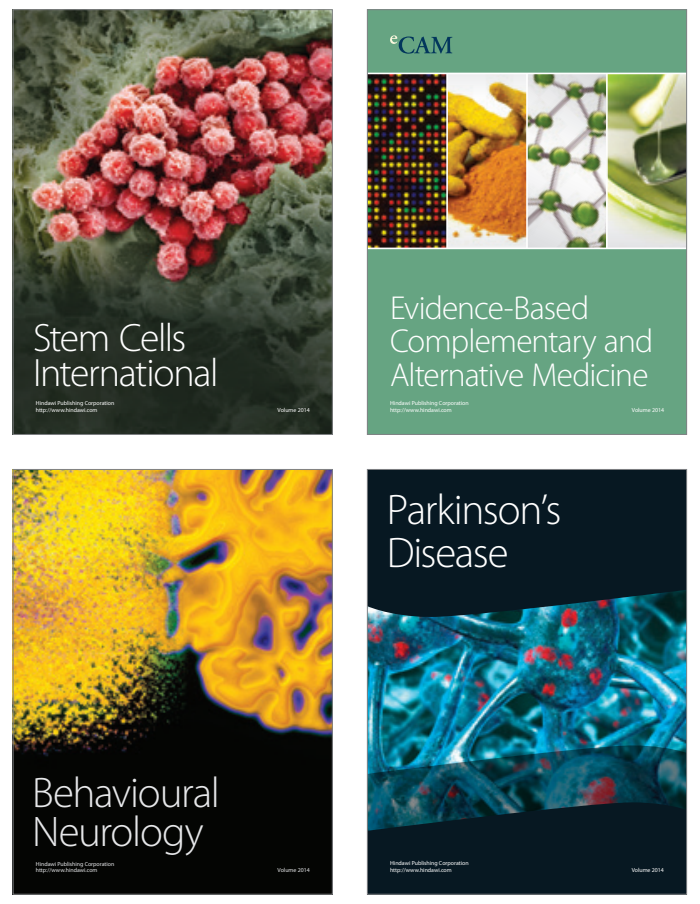
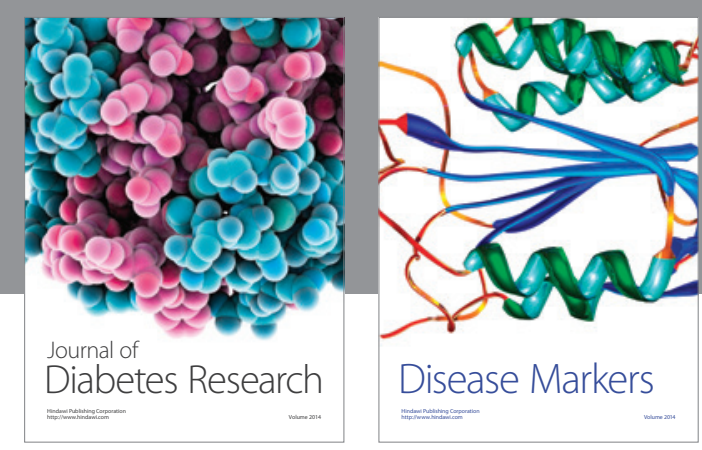

Disease Markers
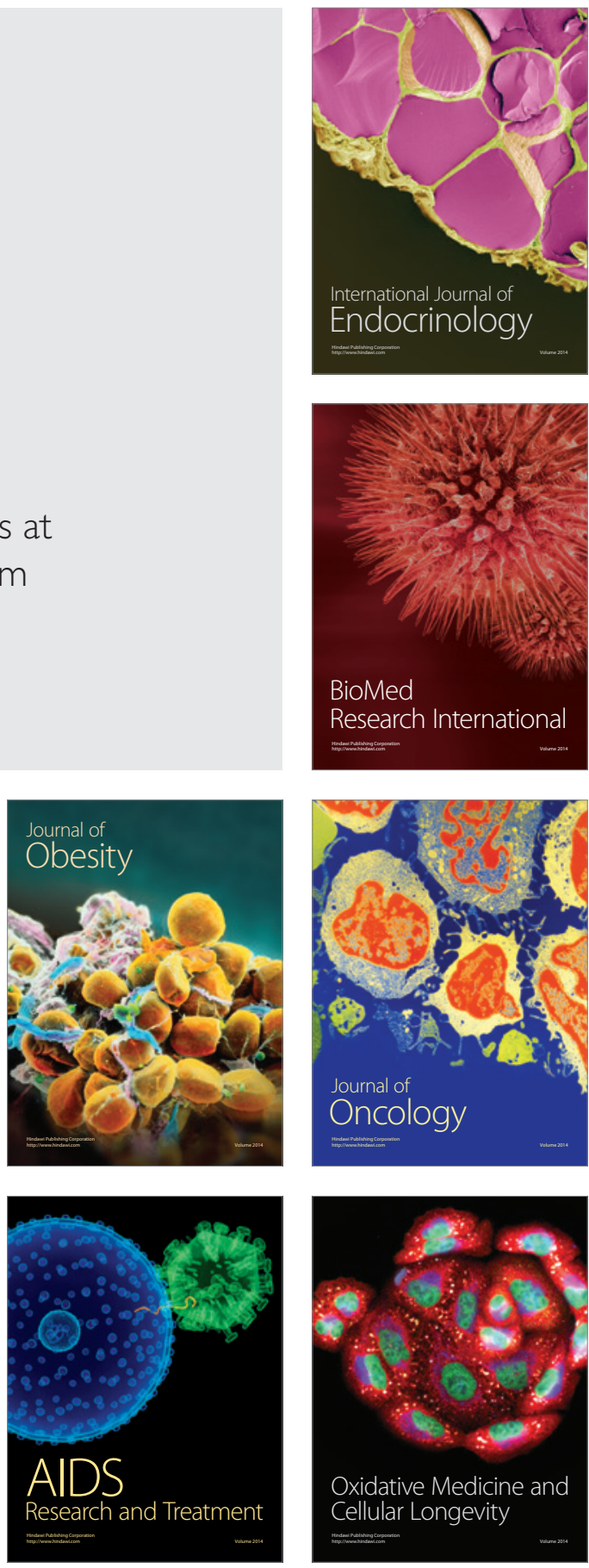